\title{
Enterocolite induzida por proteínas alimentares: uma etiologia rara
}

Maria Carlos Janeiro, ${ }^{1}$ Cátia Alves, ${ }^{2}$ Sara Prates, ${ }^{2}$ Paula Leiria Pinto ${ }^{2}$

\section{RESUMO}

Introdução: A enterocolite induzida por proteínas alimentares (EIPA) é uma forma de hipersensibilidade gastrointestinal alimentar não mediada por imunoglobulina $E$, sendo provavelmente mediada por células. A fisiopatologia permanece incerta. $O$ leite de vaca e os cereais estão entre as causas mais comuns. O diagnóstico baseia-se na história clínica.

Descrição do caso: Descreve-se um caso raro de enterocolite à batata numa criança com antecedentes pessoais e familiares irrelevantes. $O$ doente recusou várias vezes a introdução da primeira sopa (cenoura e batata) e sempre que a ingeria apresentava quadro de vómitos incoercíveis com desidratação, mas sem necessidade de internamento. Os testes cutâneos por picada com extrato de batata foram negativos e a prova de provocação oral foi positiva.

Comentários: Neste contexto salienta-se a importância de reconhecer o quadro clínico de EIPA e estar alerta para a possibilidade de envolvimento de proteínas alimentares menos frequentes com o objetivo de fazer um diagnóstico precoce e evitar terapêuticas desadequadas.

Palavras-chave: Enterocolite induzida por proteínas alimentares; Alergia alimentar; Hipersensibilidade alimentar; Alergia à batata.

\section{INTRODUÇÃO}

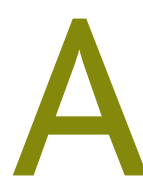
alergia alimentar é ubíqua e a sua prevalência tem vindo a aumentar nos dois primeiros anos de vida, afetando 6 a $8 \%$ das crianças. ${ }^{1-2}$ Embora muitas destas reações sejam mediadas pela imunoglobulina E (IgE) existem algumas que são mediadas imunologicamente por IgE e células (mistas) e outras apenas por células. ${ }^{1-2}$ Neste último grupo incluem-se a enteropatia induzida por proteínas alimentares (EPIPA), a proctocolite induzida por proteínas alimentares (PCIPA), a enterocolite induzida por proteínas alimentares (EIPA), a doença celíaca e a hemossiderose pulmonar induzida por alimentos..$^{1-3}$

A EIPA é uma reação de hipersensibilidade alimentar não mediada por IgE, cujo desenvolvimento após o primeiro ano de vida é raro, apesar de existirem casos descritos em crianças mais velhas e adultos. ${ }^{4}$ Caracteriza-se pela presença de sintomas gastrointestinais (ti-

1. Departamento de Pediatria, Hospital Prof. Doutor Fernando Fonseca, EPE - Amadora.

2. Serviço de Imunoalergologia, Área de Pediatria Médica, Hospital Dona Estefânia, Centro Hospitalar de Lisboa Central (CHLC), EPE. picamente vómitos e diarreia profusos e repetidos) e uma resposta inflamatória sistémica. Entre os principais alimentos implicados estão o leite de vaca, a soja e os cereais, mas existem casos descritos com outros alimentos sólidos como legumes, frutas, carne, peixe e marisco. ${ }^{6-7}$

Descreve-se o caso clínico de uma criança com enterocolite induzida por batata e faz-se, a este propósito, uma breve revisão da literatura sobre o tema.

\section{DESCRIÇÃO DE CASO}

Criança de 16 meses de idade, do sexo masculino, ex-prematuro de 33 semanas, índice de APGAR 5/8/10. Sem antecedentes pessoais e familiares de atopia. Manteve aleitamento materno exclusivo até aos seis meses, altura em que iniciou a diversificação alimentar com sopa de legumes (a primeira sopa com batata e cenoura). A introdução alimentar foi difícil, sempre com recusa alimentar e vómitos alimentares. Após várias tentativas sem sucesso foi substituída a batata por batata-doce, com boa tolerância. Aos oito meses de idade foi feita nova tentativa de reintrodução de batata na sopa 
e, cerca de duas horas após a ingestão, iniciou quadro de vómitos alimentares que se tornaram aquosos e persistentes, acompanhados de prostração e palidez cutânea generalizada, com resolução em quatro horas. Sem febre e diarreia. Não apresentava sintomas cutâneos, respiratórios ou cardiovasculares. Recorreu ao serviço de urgência (SU) onde foi diagnosticada uma gastroenterite aguda, tendo realizado hidratação oral com sucesso e sem necessidade de internamento. A referir que não apresentava queixas com os restantes alimentos já introduzidos, nomeadamente o leite de vaca, o peixe, o ovo e a carne. Desde então, estes episódios foram reproduzidos sempre que reintroduzia a batata na sopa, independentemente da quantidade administrada. Nunca ingeriu batata cozinhada de outra forma. Por vezes foi necessário recorrer ao SU, mas nunca foi internado, sendo sempre o quadro interpretado como gastroenterite aguda.

Aos 16 meses foi observado em consulta de imunoalergologia por suspeita de alergia alimentar, sem o alergénio identificado. O último episódio tinha ocorrido três meses antes. Ao exame objetivo apresentava ótimo estado geral, sem estigmas de atopia e restante exame irrelevante. Tendo em conta a existência prévia de vários episódios reprodutíveis, sempre coincidentes com a ingestão de batata, e a resolução clínica após remoção do alimento suspeito foi estabelecido o diagnóstico de EIPA a batata e recomendada a sua evicção.

Aos dois anos de idade apresentava-se clinicamente bem e sem novos episódios, mantendo evicção de batata. Realizou testes cutâneos por picada com extrato da batata que foram negativos e IgE específica indetetável. Decidiu-se então realizar PPO com sopa com batata. Após três horas iniciou quadro de vómitos alimentares abundantes, que se tornaram biliosos e persistentes, acompanhados de prostração e olhos encovados. Foi administrada fluidoterapia com bolus de solução salina ( $\mathrm{NaCl}$ a $0,9 \%) 20 \mathrm{~mL} / \mathrm{kg}$ endovenosa e, por manutenção do quadro com sinais de desidratação, apesar de hemodinamicamente estável, fez corticoide endovenoso, metilprednisolona $1 \mathrm{mg} / \mathrm{kg}$, com resolução completa do quadro após duas horas (duração total: quatro horas). Foi recomendada dieta ligeira e reforço hídrico, com manutenção da evicção da batata da dieta.

Aos três anos repetiu PPO com sopa de batata que foi negativa, pelo que reintroduziu a batata na dieta.
Não apresentou reações tardias. Manteve seguimento na consulta de imunoalergologia durante um período de um ano, sem registo de intercorrências.

\section{COMENTÁRIO}

A EIPA é uma entidade de difícil diagnóstico; o mecanismo fisiopatológico permanece incerto. Segundo os estudos mais recentes, a doença resulta de defeitos na função imunológica e de barreira do tubo digestivo. A inflamação local induzida pela ingestão do alergénio alimentar leva ao aumento da permeabilidade intestinal e desvio de fluídos, resultando na sintomatologia. A resposta inflamatória induzida pelos alergénios alimentares nestes doentes envolve diferentes tipos celulares, com ativação de células mononucleares no sangue periférico, aumento da produção do fator de necrose tumoral $\alpha$ (TNF- $\alpha$ ) e diminuição da expressão dos recetores do fator de transformação do crescimento $\beta$ (TGF- $\beta 1$ ). A resposta imunológica humoral também pode estar envolvida na fisiopatologia da EIPA, com um aumento da IgA específica e uma diminuição das imunoglobulinas $\mathrm{G}_{4}\left(\mathrm{IgG}_{4}\right)$ específicas. ${ }^{8}$

A EIPA desenvolve-se principalmente até aos 12 meses de vida com a introdução das proteínas alimentares ou durante a diversificação alimentar, como aconteceu no caso apresentado. A sua apresentação clínica difere consoante a doença se instale de forma aguda, quando o alimento é ingerido de forma intermitente, ou crónica, em que o alimento faz parte da dieta diária. ${ }^{9} \mathrm{~A}$ forma aguda é geralmente mais frequente do que a crónica.

Manifesta-se tipicamente por vómitos e diarreia profusos e repetidos. Outras manifestações clínicas de EIPA incluem diarreia sanguinolenta, prostração, distensão abdominal, palidez, hipotermia, desidratação e hipotensão arterial. A maioria dos lactentes com sintomas de EIPA aparentam estar gravemente doentes e 15-20\% desenvolvem hipotensão com necessidade de hospitalização. ${ }^{4-5}$ Dada a ausência de sintomas respiratórios e cutâneos, ao início tardio das manifestações clínicas relativamente à ingestão do alimento precipitante e à evolução clínica rápida, muitos casos são inicialmente considerados como sepsia, alterações metabólicas ou doença abdominal aguda.

Os critérios de diagnóstico de EIPA, propostos atualmente, são os seguintes: ${ }^{4}$ 
QUADRO I. Protocolo de prova de provocação oral na enterocolite induzida por proteínas alimentares proposto por Stephanie Leonard e Colaboradores ${ }^{10}$

Protocolo de prova de provocação oral

1. Deve estar assegurada supervisão médica, acesso endovenoso, disponibilidade imediata de fluídos endovenosos

2. Sinais vitais basais; leucograma com contagem de neutrófilos

3. Administração gradual de proteínas alimentares $0,06-0,6 \mathrm{~g} / \mathrm{kg}$ de peso corporal em 3 doses iguais (primeira hora); não exceder o total de $3 \mathrm{~g}$ de proteínas ou $10 \mathrm{~g}$ de alimento total $(100 \mathrm{~mL}$, se líquido) para uma dose inicial

4. Se não ocorrer nenhuma reação em 2-3 horas administrar uma dose de alimento adequada à idade, seguida de até 6 horas de observação

5. A maioria dos doentes com PPO positiva requer tratamento com fluídos e corticoides endovenosos. Hidratação endovenosa: $20 \mathrm{~mL} / \mathrm{kg}$, bolus de $\mathrm{NaCl}$ 0,9\%. Corticoides: metilprednisolona, $1 \mathrm{mg} / \mathrm{kg}$ endovenoso (máximo 60-80mg)

\section{- Critérios major:}

a. Vómitos recorrentes ou diarreia que surgem até seis horas após a ingestão alimentar;

b. Ausência de sintomas cutâneos ou respiratórios que sugiram uma reação mediada por IgE;

c. A remoção do alimento causal resulta na resolução dos sintomas;

d. A reexposição ou uma PPO com o alimento em causa provoca os sintomas típicos.

- Critérios minor (não necessariamente presentes):

a. Hipotensão;

b. Letargia, palidez ou hipotonia;

c. Testes cutâneos negativos e IgE específica indetetável;

d. Ausência de febre ou hipotermia $\left(<36^{\circ} \mathrm{C}\right)$.

A PPO é o gold-standard do diagnóstico de EIPA. No entanto, a sua realização é obrigatória apenas se a história não for clara. É um procedimento considerado de alto risco, devendo ser efetuada num local onde esteja assegurada vigilância médica, um acesso endovenoso e possa ser rapidamente reposto o equilíbrio hidroeletrolítico em caso de reação positiva. No Quadro 1 descrevemos um exemplo de protocolo para realizar uma PPO, proposto por Stephanie Leonard e colaboradores. ${ }^{10}$

A PPO é considerada positiva no caso de se desenvolverem os sintomas e/ou achados laboratoriais típicos. Os sintomas incluem vómitos (início entre uma a três horas), prostração (início entre uma a três horas) e diarreia (início entre duas a dez horas). Os achados laboratoriais incluem neutrofilia ( $>3500$ células $/ \mu \mathrm{L}$ ) com pico às seis horas após a reação e, nas fezes, a presença de leucócitos, sangue visível ou oculto e/ou eosinófilos. Cerca de $50 \%$ das PPO positivas requerem tratamento. ${ }^{11}$

A terapêutica de primeira linha no caso de uma PPO positiva consiste na administração endovenosa de soro fisiológico (20mL/kg) em bolus. Nas reações graves (vómitos repetidos, diarreia profusa, prostração, hipotensão e/ou hipotermia) também pode ser dado corticoide endovenoso para ajudar a reduzir a inflamação intestinal mediada pelas células T.3,9 Recentemente tem sido descrita a utilização de ondansetron por via endovenosa, intramuscular ou oral com bons resultados, mas são necessários mais estudos. ${ }^{4}$

No caso clínico apresentado, o diagnóstico baseou-se na história clínica, na reprodutibilidade dos sintomas com a exposição e na sua resolução após remoção do alimento precipitante. Em relação à PPO com batata considerou-se que era desnecessária para o diagnóstico, tendo sido realizada mais tarde, no seguimento, para avaliação da aquisição de tolerância.

Como no caso apresentado, a maioria dos doentes apresenta testes cutâneos por picada negativos e IgE específicas indetetáveis na altura do diagnóstico, mas cerca de $21 \%$ dos doentes com EIPA induzida por alimentos sólidos e 18 a $30 \%$ dos doentes com EIPA induzida por leite de vaca ou soja desenvolvem, mais tarde, IgE específicas detetáveis. ${ }^{12-13}$ Nestes casos existe tendência para um curso de doença mais prolongado e podem surgir sintomas de tipo imediato, mediados por IgE. Para estes casos, Sicherer propôs a designação de EIPA 


\begin{tabular}{|c|c|c|c|}
\hline \multicolumn{4}{|c|}{ Reações de hipersensibilidade gastrointestinal não mediadas por IgE ou mistas } \\
\hline Patologia & Orgão-alvo & IgE mediada? & Sintomas \\
\hline Esofagite eosinofílica & Esófago & $\begin{array}{l}\text { Sim e/ou mediada } \\
\text { por células }\end{array}$ & $\begin{array}{l}\text { Refluxo gastroesofágico, disfagia, dor abdominal, } \\
\text { impacto alimentar }\end{array}$ \\
\hline Gastroenterite eosinofílica & Estômago, jejuno/íleo & $\begin{array}{l}\text { Sim e/ou mediada } \\
\text { por células }\end{array}$ & $\begin{array}{l}\text { Dor abdominal recorrente, vómitos intermitentes, } \\
\text { perda ponderal }\end{array}$ \\
\hline $\begin{array}{l}\text { Proctocolite induzida por } \\
\text { proteínas alimentares }\end{array}$ & Reto, cólon sigmoide & Não & $\begin{array}{l}\text { Sangue visível ou oculto nas fezes; tipicamente } \\
\text { assintomática }\end{array}$ \\
\hline $\begin{array}{l}\text { Enteropatia induzida por } \\
\text { proteínas alimentares }\end{array}$ & Jejuno/íleo & Não & $\begin{array}{l}\text { Diarreia ou esteatorreia, distensão abdominal, } \\
\text { perda ponderal, náuseas ou vómitos }\end{array}$ \\
\hline $\begin{array}{l}\text { Enterocolite induzida por } \\
\text { proteínas alimentares }\end{array}$ & Jejuno/íleo, cólon & Não & Vómitos, diarreia, desidratação, choque \\
\hline
\end{tabular}

atípica, usada recentemente por vários autores. ${ }^{14}$ Os testes epicutâneos (TE) têm sido sugeridos como uma ferramenta promissora no diagnóstico de EIPA; no entanto, são necessários mais estudos. ${ }^{15}$

Em relação ao diagnóstico diferencial da EIPA, apesar de esta ser considerada a hipersensibilidade gastrointestinal mais grave, é necessário não esquecer os outros tipos de hipersensibilidade não mediada por IgE ou mista, como EPIPA, PCIPA e gastroenteropatias esosinofílicas alérgicas, apresentadas no Quadro 2.

A instalação aguda de vómitos, diarreia e desidratação pode imitar uma gastroenterite viral ou intoxicação alimentar. A ocorrência repetida destes episódios após ingestão de um determinado alimento deverá alertar para o diagnóstico. A desidratação aguda e a prostração podem, por vezes, simular uma sepsia, sendo muitas vezes usadas terapêuticas agressivas e desadequadas. A anafilaxia pode apresentar-se com vómitos e diarreia agudos; no entanto, os sintomas iniciam-se habitualmente 30 minutos a uma hora após a ingestão, enquanto os sintomas de EIPA se iniciam tipicamente uma a três horas após a ingestão. ${ }^{14}$ Quando há acidose metabólica, a EIPA pode ser confundida com o primeiro sinal de uma doença metabólica. Nos recém-nascidos, a combinação de sintomas abdominais agudos, sinais de choque e a presença de gás intramural na radiografia abdominal pode imitar a enterocolite necrosante neonatal, daí a necessidade de um elevado grau de suspeição diagnóstica para evitar atitudes terapêu-

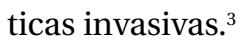

O tratamento da doença consiste na remoção do alimento precipitante da dieta. No seguimento é recomendada a realização de PPO para avaliação de aquisição de tolerância a cada 12 a 18 meses nos doentes sem contactos acidentais recentes. ${ }^{14}$ No entanto, estudos recentes sugerem que alguns lactentes ou crianças irão ultrapassar mais cedo e defendem a sua realização mais precoce. ${ }^{16}$

O diagnóstico precoce e a evicção do alimento em causa são fundamentais para prevenir terapêuticas desadequadas. É necessário um acompanhamento rigoroso para determinar o momento em que os alimentos podem voltar a ser introduzidos na dieta.

\section{REFERÊNCIAS BIBLIOGRÁFICAS}

1. Sharma HP, Bansil S, Uygungil B. Signs and symptoms of food allergy and food-induced anaphylaxis. Pediatr Clin North Am. 2015;62(6):1377-92.

2. Mansoor DK, Sharma HP. Clinical presentations of food allergy. Pediatr Clin North Am. 2011;58(2):315-26.

3. Cruz C, Didenko I, Ferreira F, Inácio F. Enterocolite induzida por proteínas alimentares [Food protein-induced enterocolitis syndrome]. Rev Port Imunoalergol. 2014;22(1):11-21. Portuguese

4. Leonard SA, Nowak-W grzyn A. Food protein-induced enterocolitis syndrome. Pediatr Clin North Am. 2015;62(6):1463-77.

5. Mehr S, Kakakios A, Frith K, Kemp AS. Food protein-induced enterocolitis syndrome: 16-year experience. Pediatrics. 2009;123(3):e459-64.

6. Kabuki T, Joh K. Extensively hydrolyzed formula (MA-mi) induced ex- 
acerbation of food protein-induced enterocolitis syndrome (FPIES) in a male infant. Allergol Int. 2007;56(4):473-6.

7. Sopo SM, Giorgio V, Dello lacono I, Novembre E, Mori F, Onesimo R. A multicentre retrospective study of 66 Italian children with food protein-induced enterocolitis syndrome: different management for different phenotypes. Clin Exp Allergy. 2012;42(8):1257-65.

8. Caubet JC, Nowak-W grzyn A. Current understanding of the immune mechanisms of food protein-induced enterocolitis syndrome. Expert Rev Clin Immunol. 2011;7(3):317-27.

9. Leonard SA, Nowak-W grzyn A. Clinical diagnosis and management of food protein-induced enterocolitis syndrome. Curr Opin Pediatr. 2012;24(6):739-45.

10. Leonard SA, Nowak-W grzyn A. Food protein-induced enterocolitis syndrome: an update on natural history and review of management. Ann Allergy Asthma Immunol. 2011;107(2):95-101.

11. Nowak-Wegrzyn A, Muraro A. Food protein-induced enterocolitis syndrome. Curr Opin Allergy Clin Immunol. 2009;9(4):371-7.

12. Katz Y, Goldberg MR, Rajuan N, Cohen A, Leshno M. The prevalence and natural course of food protein-induced enterocolitis syndrome to cow's milk: a large-scale, prospective population-based study. J Allergy Clin Immunol. 2011;127(3):647-53.

13. Nowak-Wegrzyn A, Sampson HA, Wood RA, Sicherer SH. Food proteininduced enterocolitis syndrome caused by solid food proteins. Pediatrics. 2003;111(4 Pt 1):829-35.
14. Sicherer SH. Food protein-induced enterocolitis syndrome: case presentations and management lessons. J Allergy Clin Immunol. 2005;115(1):149-56

15. Järvinen KM, Caubet JC, Sickles L, Ford LS, Sampson HA, Nowak-W grzyn A. Poor utility of atopy patch test in predicting tolerance development in food protein-induced enterocolitis syndrome. Ann Allergy Asthma Immunol. 2012;109(3):221-2.

16. Hwang JB, Sohn SM, Kim AS. Prospective follow-up oral food challenge in food protein-induced enterocolitis syndrome. Arch Dis Child. 2009;94(6):425-8.

\section{CONFLITOS DE INTERESSE}

Os autores declaram a inexistência de conflitos de interesse.

\section{FONTE FINANCIADORA}

Não existiram fontes externas de financiamento para a realização deste artigo.

\author{
ENDEREÇO PARA CORRESPONDÊNCIA \\ Maria Carlos Janeiro \\ E-mail: maria_janeiro@sapo.pt \\ Recebido em 12-07-2016 \\ Aceite para publicação em 20-08-2017
}

\section{ABSTRACT}

\section{FOOD PROTEIN-INDUCED ENTEROCOLITIS SYNDROME: A RARE ETIOLOGY}

Introduction: Food protein-induced enterocolitis syndrome (FPIES) is a non-immunoglobulin E mediated gastrointestinal food hypersensitivity, probably mediated by cells. The pathophysiological mechanism remains unclear. Cow's milk and cereals are among the most common causes of FPIES. The diagnosis is based on clinical history.

Case description: We report a rare case of enterocolitis with potato in an infant with irrelevant family and neonatal history. The patient refused several times to eat the first soup (carrot and potato) and when he ingested it he had profuse vomiting with dehydration, but without the need for hospitalization. The skin prick tests with potato extract were negative and the oral food challenge was positive.

Comments: The recognition of the clinical manifestations of FPIES and the awareness of the possible involvement of less common food proteins are crucial for the early diagnosis, avoiding inadequate diagnostic and therapeutic procedures.

Keywords: Food protein-induced enterocolitis syndrome; Food allergy; Food hypersensitivity; Potato allergy. 